- Vitreous hemorrhage may be an important cause of visual impairment in malaria patient besides cortical blindness and optic neuritis ${ }^{[1]}$

- In India, in the malaria post-resurgent era, the complications are not likely to occur as early as it used to occur in early 1990's outbreaks but, quite late after about an interval of a week or two, as it happened in this case, if the patient is not treated promptly in the initial stage. These complications are documented/observed in case of jaundice/hepatitis and renal failure as is the condition in the present case

- Thrombocytopenia is also a feature of severe malaria and most of the times decreased platelets counts are also associated with abnormal function. A correlation with severity of malaria with thrombocytopenia has also been described ${ }^{[2,3]}$

- The view expressed in the commentary that plasmodium vivax malaria may not be benign malaria was argued by Picot in $2006^{[4]}$ is good but a landmark study in this subject was also documented by Kochar et al., in the same year ${ }^{[5]}$

- So there is a need of the hour to treat each and every patient of malaria at the onset of fever/first symptoms so as to avoid such complications.

\section{Life threatening intracranial hemorrhages in malaria}

\begin{abstract}
Khichar Shubhakaran
Department of Neurology, Mahatma Gandhi Hospital, Dr. S. N. Medical College, Jodhpur, Rajasthan, India

Address for correspondence: Dr. Khichar Shubhakaran, House No. - 22/9, Umaid Hospital Campus, Jodhpur - 342001 , Rajasthan, India Email: drkhicharsk@gmail.com
\end{abstract}

\section{References}

The article entitled "Extradural hematoma in plasmodium vivax malaria; Are we alert to detect?", published in August 2013 online issue of our esteemed journal JNRP (Vol 4. issue 5, page 145-146), is an excellent documentation. In the same issue the commentary by $S J$ Khan has further elaborated the condition. Here I would like to share my views which would further enlighten the condition.

- Malaria causes various hematological and hemorrhagic complications with thrombocytopenia, among which the ocular and the intracranial hemorrhagic complications are rare but are more so fatal compared to general bleeding complications

- If intracranial or subdural/extradural hematomas are not recognized and treated promptly with correction of associated hematological complications and evacuation of hematoma, it may be potentially fatal
1. Kochar DK, Shubhakaran, Kochar SK, Vyas SP. Vitreous hemorrhage in falciparum malaria. J Assoc Physicians India 1997;45:670.

2. Kochar DK, Kochar SK, Agarwal RP, Sabir M, Nayak KC, Agrawal TD, et al. The changing spectrum of severe falciparum malaria: A clinical study from Bikaner (Northwest India). J Vector Borne Dis 2006;43:104-8.

3. Shubhakaran K, Jakhar R. Malarial Hepatitis. J Assoc Physicians India 2005;53:653.

4. Picot S. Is Plasmodium vivax still a paradigm for uncomplicated malaria? Med Mal Infect 2006;36:406-13.

5. Kochar DK, Saxena V, Singh V, Kochar SK, Kumar SV, Das A. Plasmodium vivax malaria. Emerg Infect Dis 2005;11:132-4.

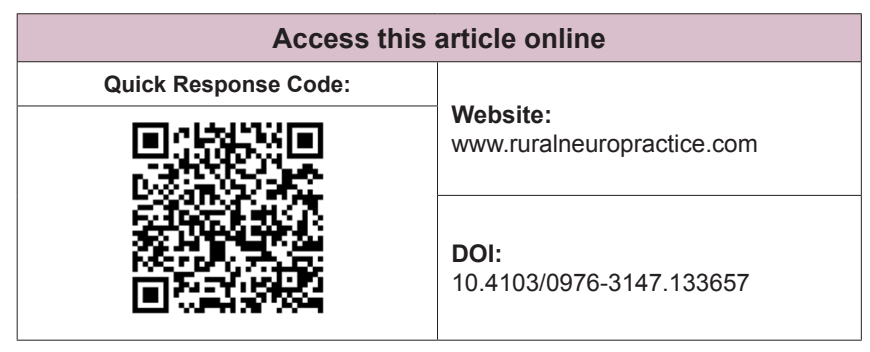

